\title{
Quantitative analysis of nucleolar chromatin distribution in the complex convoluted nucleoli of Didinium nasutum (Ciliophora)
}

\author{
Olga G. Leonova', Bella P. Karajan², Yuri F. Ivlev , Julia L. Ivanova', Sergei O. Skarlato² and Vladimir I. Popenko ${ }^{1 *}$ \\ ' Engelhardt Institute of Molecular Biology, Russian Academy of Sciences, Vavilov str. 32, Moscow 119991, Russia \\ 2 Institute of Cytology, Russian Academy of Sciences, Tikhoretsky av. 4, St. Petersburg 194064, Russia \\ 3 Severtsov Institute of Ecology and Evolution, Russian Academy of Sciences, Leninsky av. 33, Moscow 119071, Russia
}

\begin{abstract}
We have earlier shown that the typical Didinium nasutum nucleolus is a complex convoluted branched domain, comprising a dense fibrillar component located at the periphery of the nucleolus and a granular component located in the central part. Here our main interest was to study quantitatively the spatial distribution of nucleolar chromatin structures in these convoluted nucleoli. There are no "classical" fibrillar centers in D.nasutum nucleoli. The spatial distribution of nucleolar chromatin bodies, which play the role of nucleolar organizers in the macronucleus of D.nasutum, was studied using 3D reconstructions based on serial ultrathin sections. The relative number of nucleolar chromatin bodies was determined in macronuclei of recently fed, starved D.nasutum cells and in resting cysts. This parameter is shown to correlate with the activity of the nucleolus. However, the relative number of nucleolar chromatin bodies in different regions of the same convoluted nucleolus is approximately the same. This finding suggests equal activity in different parts of the nucleolar domain and indicates the existence of some molecular mechanism enabling it to synchronize this activity in D. nasutum nucleoli. Our data show that $D$. nasutum nucleoli display bipartite structure. All nucleolar chromatin bodies are shown to be located outside of nucleoli, at the periphery of the fibrillar component.
\end{abstract}

Key words: 3D reconstruction; ciliates; electron microscopy; macronucleus; nucleoli

\section{INTRODUCTION}

The nucleolus is a highly dynamic subnuclear domain where ribosomal RNA (rRNA) synthesis, rRNA processing and assembly of ribosomal subunits take place. In a typical cell nucleus nucleoli are formed around the ribosomal DNA (rDNA) repeats arranged around the nucleolar-organizing regions (NORs) on one or several chromosomes (Scheer and Hock, 1999; Carmo-Fonseca et al., 2000, Raska et al., 2006). In some cells such as the slime mold Dictyostelium and amphibian oocytes, the nucleoli are formed around extrachromosomal rDNA (Raikov, 1989; Thiebaud, 1979).

Extensive electron microscopic studies revealed the same general principles of nucleolar organization in the vast majority of species studied. Three main constituent parts of nucleoli, usually arrayed more or less concentrically, can be distinguished in the nucleus: (1) the fibrillar centers, (2) the dense fibrillar component, and (3) the granular component (Mosgoeller, 2004; Thiry et al., 2011). On ultrathin sections, the fibrillar centers have a rounded shape and are formed by densely packed fibrillar material. In the interphase nucleus, these centers are apparently the equivalent of NORs of individual chromosomes (Goessens, 1984; Zatsepina et al., 1988). Transcription of ribosomal genes presumably takes place at the border of fibrillar centers and the dense fibrillar component, whereas the surrounding dense fibrillar component corresponds to the nucleolar regions where maturation of pre-rRNA transcripts occurs (Cheutin et al., 2004; Guillot et al., 2005). The last stages of assembly of preribosomal particles preceding their transport to the cytoplasm take place in the granular component. This organization of the nucleolus implies that the vector of rRNA processing is directed from the inner part of the nucleolus to its periphery (Fromont-Racine et al., 2003; Nazar, 2004; Derenzini et al., 2006).

Thiry et al. $(2005,2011)$ carried out a detailed comparative examination of the nucleolar ultrastructure in various eukaryotic species and came to the conclusion that tripartite nucleoli containing all three components are only typical of amniotic vertebrates; in all other eukaryotes bipartite nucleoli are present. In such nucleoli only two nucleolar compartments can be unambiguously identified: a fibrillar zone, surrounded by a granular zone (review, Thiry and Lafontaine, 2005).

In contrast to higher organisms, nucleolar domains of single-celled protists have received much less attention. The most promising models for these studies can be found among ciliates. Ciliated protists contain two morphologically and functionally different types of nuclei in a single cell - microand macronuclei. The micronuclei are inert diploid germ line nuclei which lack nucleoli, whereas the macronuclei are transcriptionally active somatic nuclei with prominent nucleolar compartments (see Raikov, 1995).

All ciliate species studied so far can be divided into two groups: the ciliates with macronuclear DNAs of subchromosomal size (up to several hundred $\mathrm{kbp}$ ), and those with gene-sized ( 0.4 to $20 \mathrm{kbp}$ ) macronuclear DNAs which show the characters of mini-chromosomes. Thus macronuclei provide opportunity for studies of spatial organization of nucleoli in the absence of typical chromosomes.

The macronucleus of the ciliate Didinium nasutum (Fig. 1) contains DNA of subchromosomal size (Popenko et al., 2007). The nucleolar domains in this somatic nucleus are 
distributed among numerous compact chromatin bodies 90$250 \mathrm{~nm}$ in diameter (Karajan et al., 1995). 3D reconstructions based on serial ultrathin sections clearly show that nucleoli are complex convoluted, branched structures in which the fibrillar component is located at the periphery, while the granular part is in the central part of the nucleolus (Leonova et al., 2006; Popenko et al., 2008). Results from these studies led us to suggest that in D. nasutum processing of rRNAs occurs from the periphery of the nucleolus to its center. In many ciliate species, NORs look like chromatin bodies partially or completely surrounded by the fibrillar component of the nucleolus (Sabaneyeva, 1997; Sabaneyeva et al., 1984, see also references in Raikov, 1995). It has been also shown by autoradiography that NORs in D. nasutum are represented by chromatin bodies located both inside and at the boundary of nucleoli (Karadzhan, 1987).

Numerous reports in the literature demonstrate that nucleolar activity in both ciliates and higher eukaryotic cells reduces drastically under unfavorable conditions such as starvation (see references in Raikov, 1995; Engberg, 1985; Mayer and Grummt, 2005; Boulon et al., 2010). The aim of this research is to determine the exact spatial localization of nucleolar chromatin bodies in convoluted interphase $D$. nasutum nucleoli on the ultrastructural level and to compare the relative number of such bodies in the nucleoli of recently fed cells, starved cells, resting cysts and in different parts of convoluted nucleoli. To address these issues, we used 3D reconstructions to study localization of all the chromatin bodies, which corresponded to NORs by morphological criteria.

\section{METHODS}

The laboratory strain of Didinium nasutum was grown at room temperature in lettuce medium and fed with Paramecium caudatum as described earlier (Leonova et al., 2006). Ciliates cultivated in the excess of food were fixed for electron microscopy 5-7 min after the last feeding ("fed" ciliates). Part of the ciliate culture was transferred into food-free culture medium and fixed $30 \mathrm{~h}$ later ("starved" cells). Resting cysts of D. nasutum were obtained and fixed as described in (Karajan et al., 2003).

Both fed and starved cells were fixed with $2.5 \%$ glutaraldehyde in $0.1 \mathrm{M}$ phosphate buffer ( $\mathrm{pH} \mathrm{7.5)}$ for $1 \mathrm{~h}$ at room temperature, dehydrated in a graded series of alcohol and embedded in Epon-Araldite mixture. Serial ultrathin sections were obtained with an LKB III ultratome (LKB Products, Stockholm-Bromma, Sweden) and stained with uranyl acetate and lead citrate using the standard procedure. The specimens were examined in a JEM-100CX electron microscope (JEOL Ltd., Tokyo, Japan).

A regressive staining of sections with uranyl acetate -EDTA- lead citrate, which selectively contrasts ribonucleoproteins, was performed as described elsewhere (Bernhard, 1969).

Negatives of serial sections of macronucleus (20-30 items, $50-70 \mathrm{~nm}$ thick) were scanned at a final resolution of 480 pixels per $1 \mu \mathrm{m}$ of a section. The 3D reconstruction was carried out using the STERM software developed by the authors (Leonova et al., 2006). During reconstruction we took into account only structures larger than $50 \mathrm{~nm}$ in size. Six regions of macronuclei of five fed cells (reconstructed volumes varied from 48 to 418 $\mu \mathrm{m}^{3}$ ) and four regions of four starved cells (56 to $220 \mu \mathrm{m}^{3}$ ) were reconstructed. Average values were compared using a 2-tailed Student's $t$-test. The relative number of NORs, i.e. the number of nucleolar chromatin bodies per $1 \mu \mathrm{m}^{2}$ of the nucleolar surface, was calculated in 3D reconstructions by division of the number of nucleolar bodies by the area of adjacent nucleolar surface.

\section{RESULTS}

The macronucleus of recently fed interphase $D$. nasutum cells contains numerous conspicuous nucleoli that are evenly distributed throughout the nucleoplasm (Fig. 2a). The dense fibrillar component mainly occurs in the form of discrete bands or trabecules on the surface of the nucleoli, while the granular component lies inside the nucleoli, filling the space between trabeculae of the fibrillar component more or less uniformly. Figures $2 \mathrm{~b}$ and 3 display $3 \mathrm{D}$ reconstructions of the macronuclear region, corresponding to the ultrathin section shown in Figure 2a. In order to give a clear idea of nucleolar topology and reduce the overlapping of nucleolar structures, the granular component in 3D reconstructions was omitted.

$3 \mathrm{D}$ reconstructions show that the nucleoli, which normally look in single sections like individual separate structures, have actually been assembled into large convoluted nucleolar networks (Figs 2b, 3). Chromatin bodies of irregular shape and $0.09-0.25 \mu \mathrm{m}$ in size are uniformly distributed in the macronucleus (Figs 2a, 4a). Those of these bodies which are thought to correspond to NORs were determined in individual ultrathin sections by morphological criteria. Such chromatin bodies are located either inside the nucleolus, fully surrounded by the dense fibrillar component (Fig. 4b), or at the periphery of nucleoli and connected with the fibrillar component by visible chromatin threads or fibers (Figs $4 a, c$ ). These threads and fibers are of deoxyribonucleoprotein nature, since they appeared bleached in sections stained according to Bernhard's method (Bernhard, 1969), which selectively reveals ribonucleoproteins (Figs 4d, e).

$3 \mathrm{D}$ reconstructions show that all nucleolar chromatin bodies - putative NORs are located outside the nucleoli, in the nucleoplasm. No chromatin bodies were located in the inner part of the nucleoli or inside the fibrillar component. Even the chromatin bodies that seem to be located inside the nucleolus in single sections (Fig. $4 \mathrm{~b}$ ) were in fact located at the periphery, in the cavities of the fibrillar component (Fig. 3).

The structure of nucleoli in starved cells fixed $30 \mathrm{~h}$ after feeding is strikingly different from that of recently fed cells (Fig. 5a). No chromatin bodies are observed inside the nucleoli in these starved cells. 3D reconstructions (Figs 5b) show that all nucleolar chromatin bodies are located at the periphery of the nucleoli, in the nucleoplasm.

The number of NORs in the nucleoli is known to indicate the activity of ribosomal protein synthesis in both proliferating and non-proliferating cells (Jozsa et al., 1993). In D. nasutum we could not determine the exact number of nucleolar bodies per nucleolus, since most of the branched interphase nucleoli exceeded the boundaries of the reconstructed region and had an intricate shape. Therefore, we calculated the relative number of nucleolar bodies per $1 \mu^{2}$ area of the nucleolar surface and compared this parameter in recently fed and starved cells. In fed D. nasutum, the relative number of nucleolar bodies was $5.29 \pm 0.49(\mathrm{M} \pm \mathrm{SD}$, averaged over six 
reconstructions from five cells). In the starved cells, it was equal to $3.58 \pm 0.62(\mathrm{M} \pm \mathrm{SD}$, four reconstructions from four cells), i.e. 1.52 times lower (statistically significant at $\mathrm{p}<0.001$ ). The latter finding correlates well with the lower activity of the macronucleus in the starved cells (Engberg, 1985, Raikov, 1995). In addition, in resting D. nasutum cysts we detected no chromatin bodies either inside the nucleoli or at their periphery (Fig. 6). Thus there is a good correlation between the relative number of nucleolar chromatin bodies and the activity of the nucleolus.

To answer the question of whether the activity in various parts of complex convoluted D. nasutum nucleoli is different, we calculated the relative number of nucleolar chromatin bodies for the whole nucleolus and for its different parts. These values were found to be very close. For example, in the convoluted nucleolus of fed ciliates, shown in Figure 4, the mean number of nucleolar chromatin bodies per $1 \mu \mathrm{m}^{2}$ was equal to 5.57, while it varied from 5.37 to 5.8 in different parts of it (Table 1). For the nucleolus from starved D. nasutum cell (Fig. 5), the mean relative number was 3.71 and the range was $3.4-3.85$ for the four different parts of it (Table 2). The coefficient of variation in these two examples and other seven reconstructions (not shown) was less than 10\%. These data make it safe to conclude that the activity of the various parts of complex interphase $D$. nasutum nucleoli is approximately the same.

\section{DISCUSSION}

Our 3D reconstructions based on serial ultrathin sections, image analysis and computer-aided modeling clearly show that all compact chromatin bodies in the macronucleus of D. nasutum are located outside the nucleoli, in the nucleoplasm, both in recently fed and starved cells. In ciliates macronuclear rDNAs are preferentially replicated before the

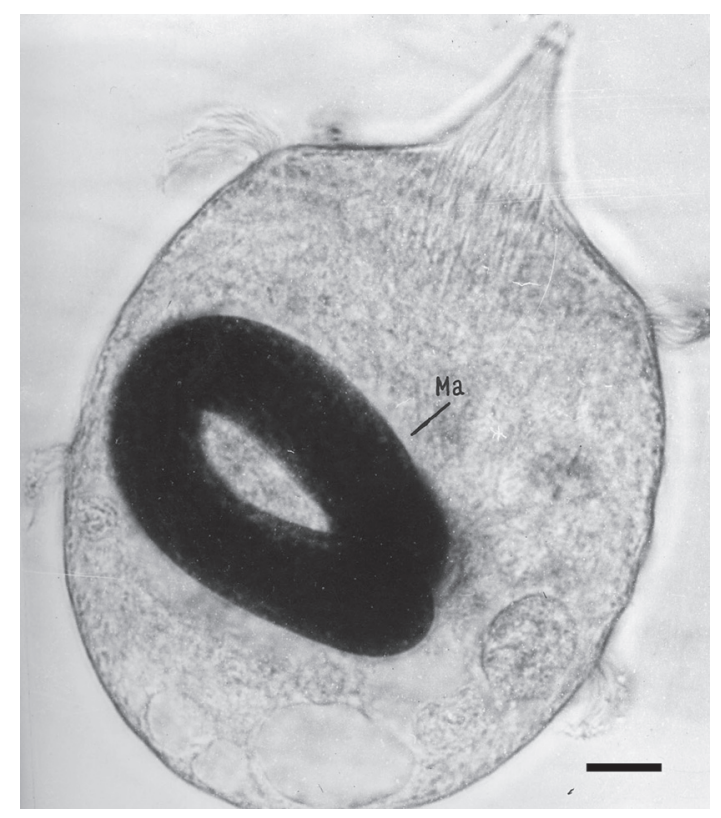

Figure 1. Didinium nasutum in the light microscope. Feulgen staining. Ma - macronucleus. Scale bar, $10 \mu \mathrm{m}$.

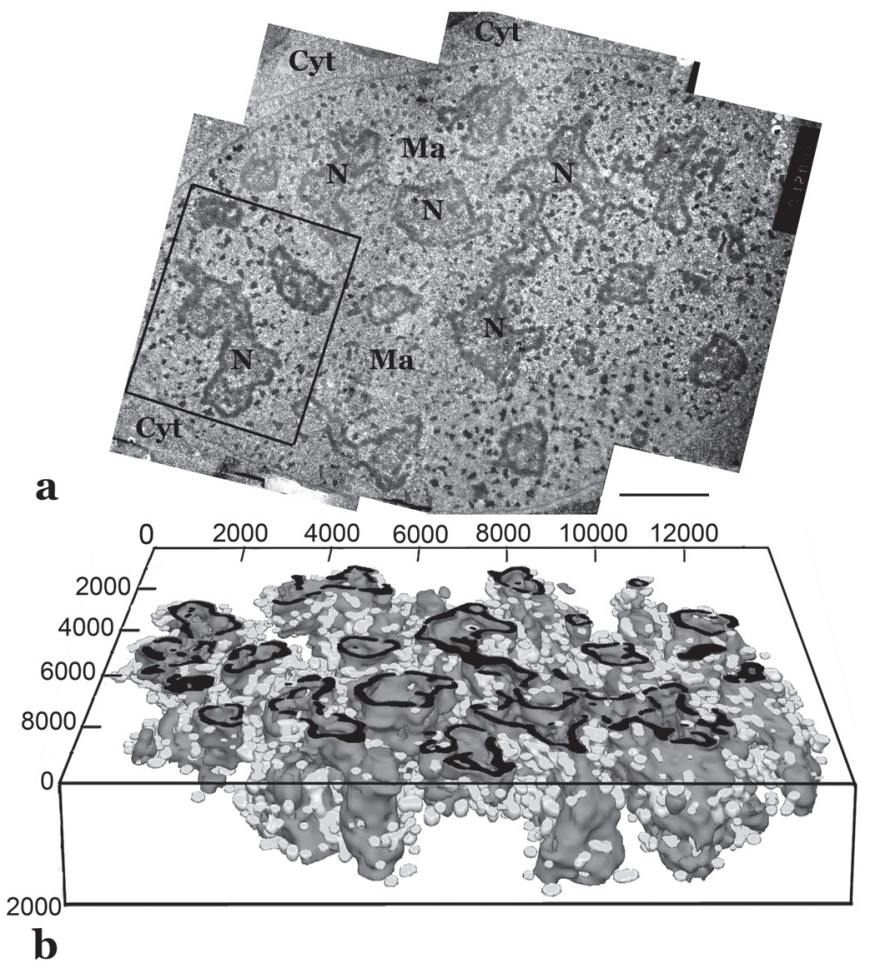

Figure 2. Nucleoli in recently fed Didinium nasutum cells. a - an ultrathin section of a macronucleus. Numerous conspicuous large nucleoli are evenly distributed throughout the nucleoplasm. Ma - nucleoplasm of macronucleus, Cyt - cytoplasm, N - nucleoli. Scale bar, $2 \mu \mathrm{m}$. b - 3D reconstruction of the macronuclear region cross-sectioned at the level corresponding to the section in Figure 1a. Only the fibrillar component and nucleolar bodies are shown. The fibrillar component in the cross section plane is tinted black to compare with the corresponding structures in Figure 1a. The distances are shown in $\mathrm{nm}$.

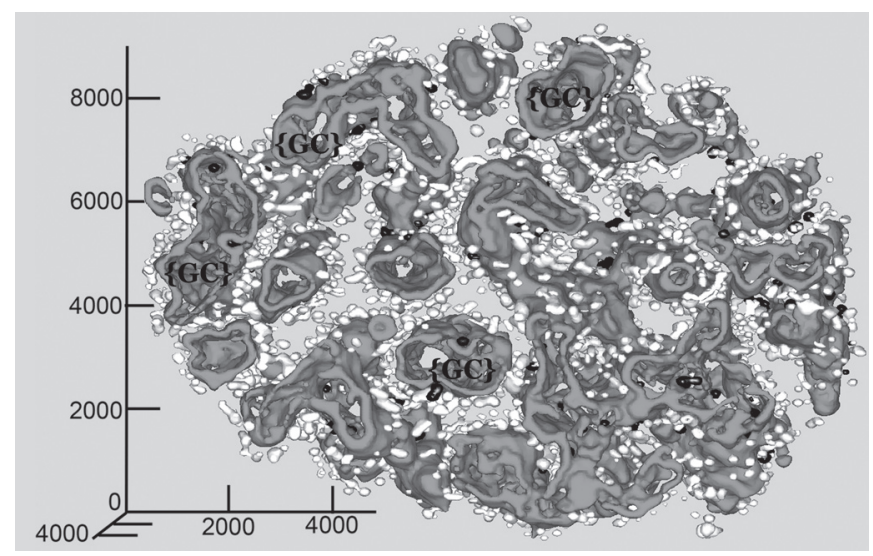

Figure 3. Top view of a 3D reconstruction of network-like branched nucleoli in fed D. nasutum cells. Only the fibrillar component (grey color) and nucleolar chromatin bodies (black and white colors) are shown. Chromatin bodies, which were completely surrounded by the fibrillar component in individual sections, are colored black. The intranucleolar space where the granular component was located is designated as $\{\mathrm{GC}\}$. The distances are shown in $\mathrm{nm}$. 
bulk of macronuclear DNA (Engberg, 1985). It was shown autoradiographically by Karadzhan (1987) that chromatin bodies at the periphery or inside the D. nasutum nucleoli were labeled at the beginning of the S-phase. Since no other chromatin structures resembling the nucleolar fibrillar centers were detected in ultrathin sections of D. nasutum, we considered these perinucleolar chromatin bodies as putative NORs. This approach is quite consistent with the data of many authors, who reported that NORs in ciliates can look like chromatin bodies, completely or partially surrounded by the
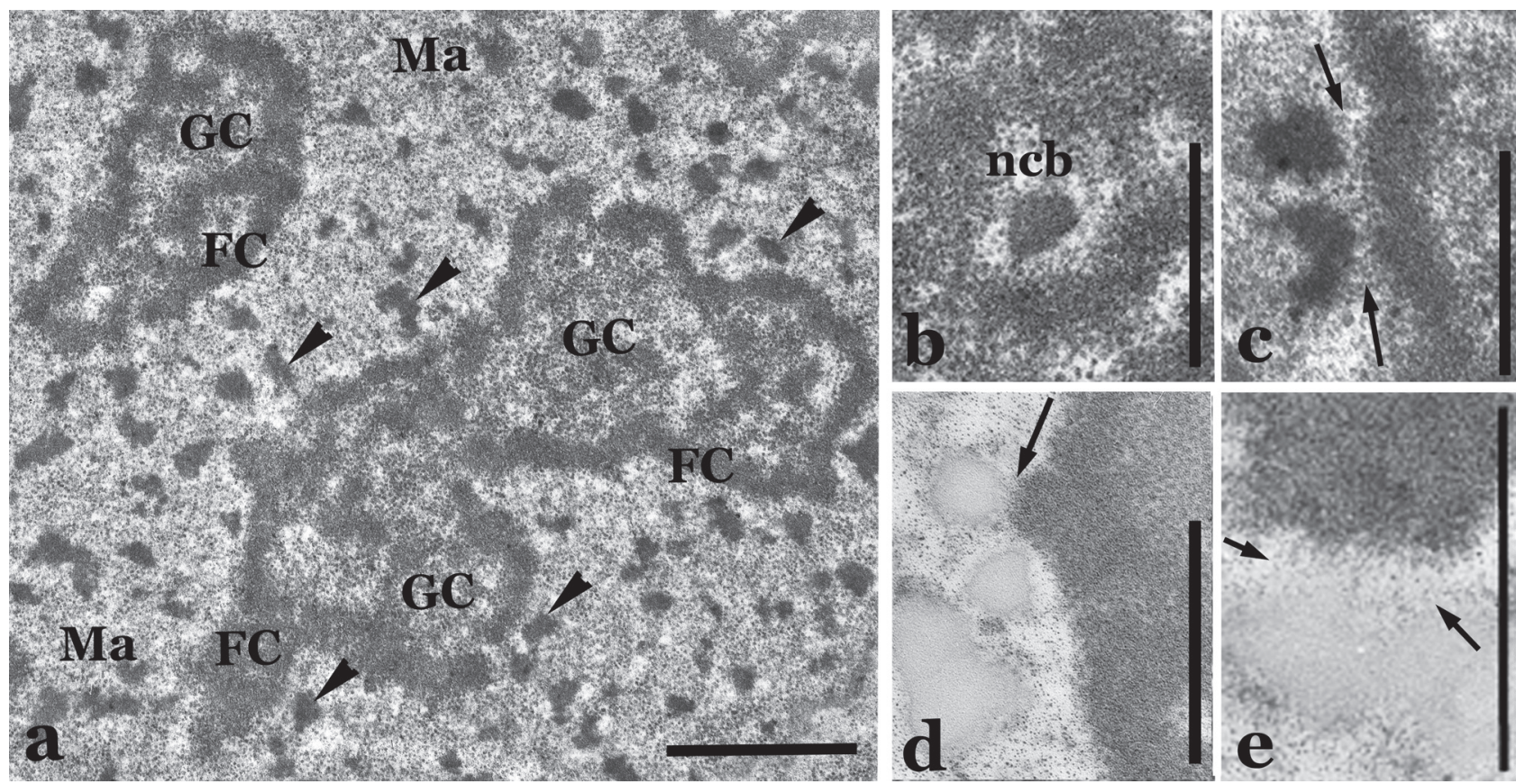

Figure 4. Nucleolar chromatin bodies in recently fed D. nasutum cells. a - a fragment of Figure 1 a at higher magnification (part of the large convoluted branchy nucleolus). The dense fibrillar component is located at the periphery and looks like discrete bands or trabecules. The granular component is in the inner part of the nucleolus. Arrowheads - chromatin bodies connected with the fibrillar component by visible chromatin threads, Ma - nucleoplasm of the macronucleus, FC - the fibrillar component, GC - the granular component. b - nucleolar chromatin body (ncb) located inside the nucleolus at higher magnification. c - nucleolar chromatin bodies located in nucleoplasm at the periphery of nucleoli and connected with the fibrillar component by visible chromatin threads (arrows). d, e- a regressive staining of sections with uranyl acetate - EDTA - lead citrate. RNPs are selectively contrasted. The chromatin threads (arrows) remain unstained. Scale bars, $1 \mu \mathrm{m}(\mathrm{a}), 0.5 \mu \mathrm{m}(\mathrm{b}-\mathrm{e})$.

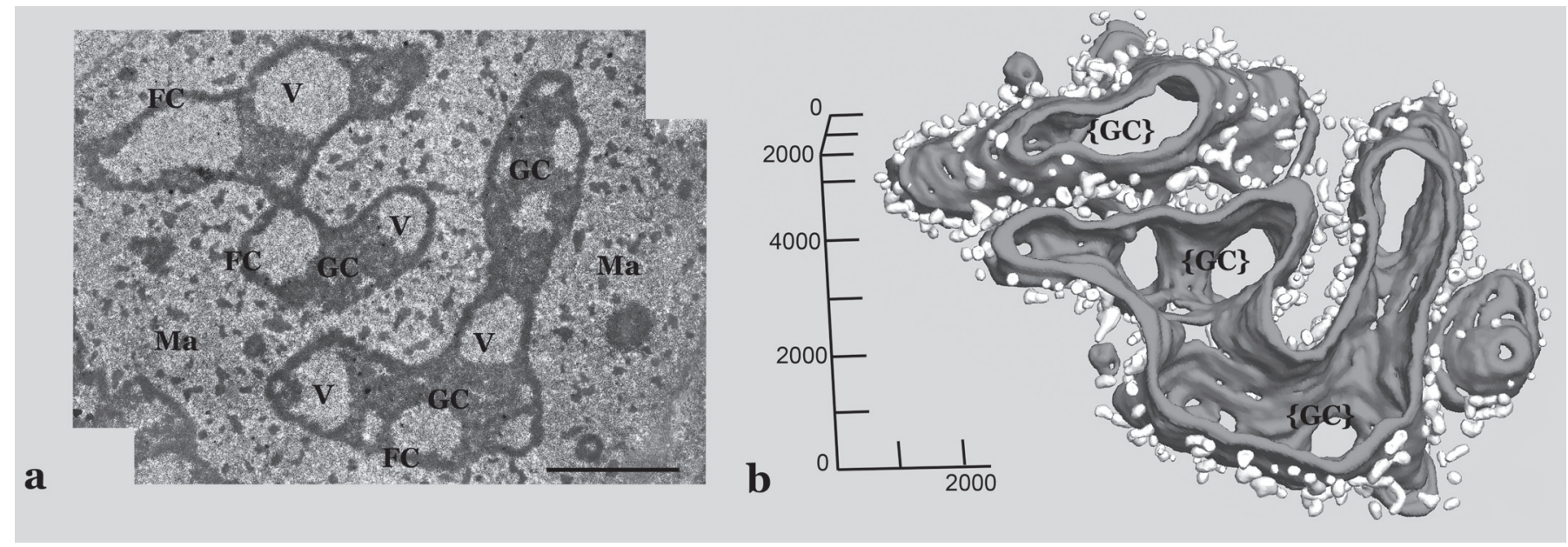

Figure 5. Nucleoli in starved D. nasutum cells. a - a single section of typical macronuclear region. Large vacuoles (V) appear in the granular component of nucleoli. No chromatin bodies are observed inside the nucleoli. Ma -macronucleus, FC - the fibrillar component, GC - the granular component. Scale bar, $2 \mu \mathrm{m}$. b -3D reconstruction of network-like branched nucleolus in fed D. nasutum cells. The fibrillar component is tinted grey, nucleolar chromatin bodies - white. The granular component is not shown. The intranucleolar space where the granular component was located is designated as $\{\mathrm{GC}\}$. The distances are shown in $\mathrm{nm}$. 
fibrillar component (references in Raikov, 1995; Sabaneyeva 1984, 1997). Results of the present study clearly show that "intranucleolar" chromatin bodies are not really localized within the constituent parts of nucleoli. In fact, the so-called

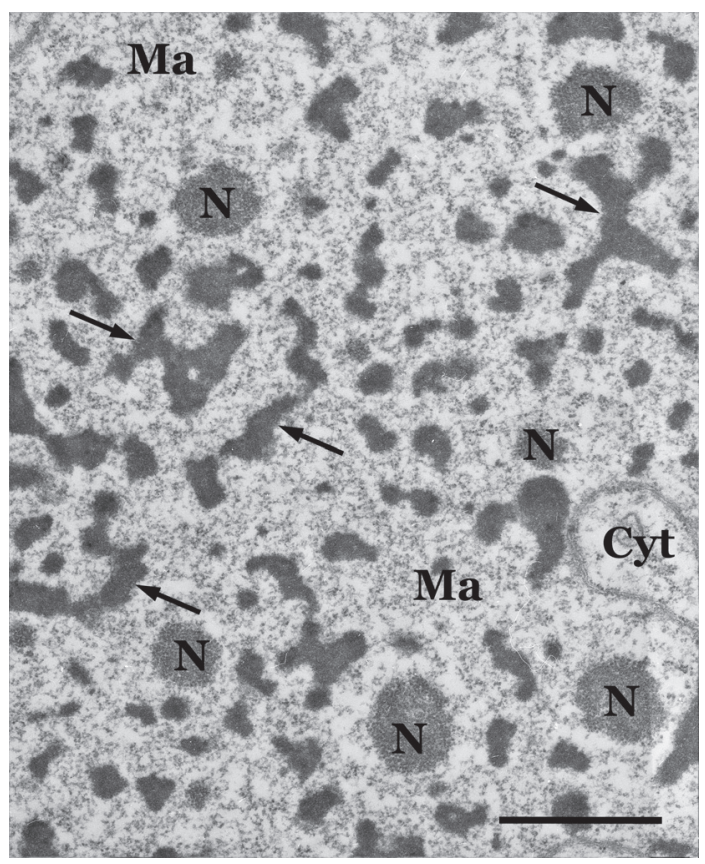

Figure 6. Fragment of the macronucleus of D. nasutum cyst. Arrows point to chromatin fibers of aggregated chromatin bodies. $\mathrm{N}$ - nucleoli, $\mathrm{Ma}$ - nucleoplasm of macronucleus, Cyt - cytoplasm. Scale bar, $1 \mu \mathrm{m}$. intranucleolar chromatin bodies appear to represent nucleolar chromatin bodies in cavities of the complex branched nucleoli. Together with the fact that the granular component is located in the inner part of convoluted nucleoli, these data strongly suggest that the vector of rRNA processing in D. nasutum is directed from the periphery to the central part of the nucleolus.

Our results are in a good agreement with the findings of Postberg et al. (2006) in the macronucleus of Stylonychia lemnae, which displays gene-sized mini-chromosomes. In this ciliate rDNAs are found to occur adjacent to, but outside the nucleoli. Thus transcription, or at least its initiation, should start within the outer domains of condensed chromatin and the subsequent processing of rRNA should occur in the interior of nucleolar domains. It was assumed that the absence of typical chromosomes determines this alternative spatial organization of the nucleolus (Postberg et al., 2006). Our data show that nucleoli within macronuclei with subchromosomal DNAs (D. nasutum) can also conduct rRNA processing in thr opposite direction compared to the "classical" nucleoli of Metazoa.

We have demonstrated that the relative number of nucleolar bodies in the branched $D$. nasutum nucleoli correlates with the functional state of these ciliates. The relative number in recently fed cells was 1.52 times greater than in starved cells. Moreover, no chromatin bodies connected with nucleolar structures were observed in cysts. These results are in accordance with the fact that the number of NORs in the nucleoli indicates the activity of ribosomal protein synthesis in both proliferating and non-proliferating cells (Jozsa et al., 1993). However, the relative number of nucleolar chromatin bodies in the whole convoluted nucleolus and in different parts of it appeared to be the same (Tables 1,2 ). Thus in D. nasutum, the synthetic activity in various parts of complex interphase nucleoli is approximately the same. It is tempting to speculate

\section{TABLE 1}

Nucleolar chromatin bodies in a complex convoluted nucleolus in recently fed D. nasutum ciliates.

\begin{tabular}{|c|c|c|c|c|c|}
\hline Parameter & $\begin{array}{l}\text { Reconstructed convoluted } \\
\text { network-like nucleolus as a whole }\end{array}$ & \multicolumn{4}{|c|}{ Fragments of the same convoluted nucleolus } \\
\hline Number of nucleolar chromatin bodies & 2433 & 175 & 1145 & 105 & 8 \\
\hline Area of fibrillar component outside, $\mu \mathrm{m}^{2}$ & 436.55 & 32.47 & 211.62 & 18.139 & 1.488 \\
\hline $\begin{array}{l}\text { Relative quantity of nucleolar chromatin bodies } \\
\text { per } 1 \mu \mathrm{m}^{2} \text { of fibrillar component outside }\end{array}$ & 5.57 & 5.52 & 5.41 & 5.8 & 5.37 \\
\hline
\end{tabular}

\section{TABLE 2}

Nucleolar chromatin bodies in a complex convoluted nucleolus of starved D. nasutum ciliates.

\begin{tabular}{|c|c|c|c|c|c|}
\hline \multirow{2}{*}{ Parameter } & \multirow{2}{*}{$\begin{array}{l}\text { Reconstructed convoluted } \\
\text { nucleolus as a whole }\end{array}$} & \multicolumn{4}{|c|}{ Fragments of the same convoluted nucleolus } \\
\hline & & 1 & 2 & 3 & 4 \\
\hline Number of nucleolar chromatin bodies & 537 & 18 & 9 & 32 & 1 \\
\hline Area of fibrillar component outside, $\mu \mathrm{m}^{2}$ & 144.64 & 5.29 & 2.52 & 8.54 & 0.26 \\
\hline $\begin{array}{l}\text { Relative quantity of nucleolar chromatin bodies per } 1 \\
\qquad \mu \mathrm{m}^{2} \text { of fibrillar component outside }\end{array}$ & 3.71 & 3.4 & 3.57 & 3.75 & 3.85 \\
\hline
\end{tabular}


that a specific molecular mechanism exists in D. nasutum which synchronizes the rRNA synthesis in different parts of the interphase nucleoli.

The classical fibrillar centers in nucleoli of higher eukaryotes are structures with low electron density composed of fine fibrils 7-10 nm in diameter (Goessens, 1984). According to Thiry at al. (2011), typical tripartite nucleoli containing all three main components (i.e. fibrillar center, dense fibrillar component and granular component) are only found in amniotic vertebrates (Thiry and Lafontaine, 2005; Thiry et al., 2011). In other eukaryotes the nucleoli are usually bicompartmentalized, where only two nucleolar compartments -fibrillar and granular components- are unambiguously identified. The absence of classical fibrillar centers in $D$. nasutum nucleoli is in agreement with these data.

In summary, we infer that both gene- and subchromosomalsize atypical chromosomes of macronuclei which lack centromeres can determine an alternative spatial organization of vectorial synthesis and processing of rRNA in ciliates.

\section{ACKNOWLEGEMENTS}

The authors are grateful to V.A. Grigoryev for technical assistance, Dr. John G. Holt (USA) for valuable criticism and proofreading of the text. This work was supported by grants no. 11-04-01967a to V.I.P and no.10-04-00943a to S.O.S from the Russian Foundation for Basic Research.

\section{REFERENCES}

BERNHARD W (1969) A new staining procedure for electron microscopical cytology. J Ultrastr Res 27:250-265.

BOULON S, WESTMAN BJ, HUTTEN S, BOISVERT F-M, LAMOND AI (2010). The Nucleolus under Stress. Mol Cell 40:216-227.

CARNO-FONSECA M, MENDES-SOARES L, CAMPOS I (2000) To be or not to be in the nucleolus. Nature Cell Biol 2:107-112

CHEUTIN T, MISTELI T, DUNDR M (2004) Dynamics of nucleolar components. In: The nucleolus. Kluwer Academic/Plenium Publishers, New York, pp. 29-40.

DERENZINI M, PASQUINELLI G, ODONOHUE MF, PLOTON D, THIRY M (2006) Structural and functional organization of ribosomal genes within the mammalian cell nucleolus. J Histochem Cytochem 54:131-145.

ENGBERG J (1985) The ribosomal RNA genes of Tetrahymena: structure and function. Europ J Cell Biol 36:133-151.

FROMONT-RACINE M, SENGER B, SAVEANU C, FASIOLO F (2003) Ribosome assembly in eukaryotes. Gene 313:17-42.

GOESSENS G (1984). Nucleolar structure. Int Rev Cytol 87:107-158.

GUILLOT PV, MARTIN S, POMBO A (2005) The organization of transcription in the nucleus of mammalian cells. In: Vision of the cell nucleus. California, Amer. Sci. Publ., pp. 95-105.
JOZSA L, KANNUS P, JARVINEN M, ISOLA J, KVIST M, LEHTO M (1993) Atrophy and regeneration of rat calf muscles cause reversible changes in the number of nucleolar organizer regions. Evidence that also in nonproliferating cells the number of NORs is a marker of protein synthesis activity. Lab Invest 69:231-237.

KARADZHAN BP (1987) Replication of rDNA in the cell cycle of the ciliate Didinium nasutum. Autoradiographic data. Doklady Akad Nauk SSSR 296:984-986.

KARAJAN BP, POPENKO VI, RAIKOV IB (1995) Organization of transcriptionally inactive chromatin of interphase macronucleus of the ciliate Didinium nasutum. Acta Protozool 34:135-141.

KARAJAN BP, POPENKO VI, LEONOVA OG (2003) Fine structure of nucleoli in the ciliate Didinium nasutum. Protistology 3:87-94.

LEONOVA OG, KARAJAN BP, IVLEV YF, IVANOVA JL, POPENKO VI (2006). Nucleolar apparatus in the macronucleus of Didinium nasutum (Ciliata): EM and 3D reconstruction. Protist 157:391-400.

MAYER C, GRUMMT I (2005) Cellular Stress and Nucleolar Function. Cell Cycle 4:1036-1038.

MOSGOELLER W (2004) Nucleolar ultrastructure in vertebrate. In: The nucleolus. Kluwer Acad./ Plenium Publ., New York., pp. 10-20.

NAZAR RN (2004) Ribosomal RNA processing and ribosome biogenesis in eukaryotes. IUBMB Life. 56:457-465.

POPENKO VI, KARAJAN BP, LEONOVA OG, IVANOVA YL (2007) Chromomeric level of chromatin organization in the macronuclei of ciliates. Tsitologiya 49:785-786.

POPENKO VI, KARAJAN BP, LEONOVA OG, SKARLATO SO, IVLEV YF, IVANOVA YL (2008) Three-dimensional structure of the ciliate Didinium nasutum nucleoli. Molecular Biology 42:455-461.

POSTBERG J, ALEXANDROVA O, LIPPS HJ (2006) Synthesis of prerRNA and mRNA is directed to a chromatin-poor compartment in the macronucleus of the spirotrichous ciliate Stylonychia lemnae. Chromosome Res 14:161-175.

RAIKOV IB (1989) Nuclear genome of the protozoa. Progress in Protistology 3:21-86.

RAIKOV IB (1995) Structure and genetic organization of the polyploid macronucleus of ciliates: a comparative review. Acta Protozool 34:151-171.

RASKA I, SHAW PJ, CMARKO D (2006) New insights into nucleolar architecture and activity. Int Rev Cytol 255:177-135.

SABANEYEVA EV, RAUTIAN MS, RODIONOV AV (1984) Demostration of active nucleolar organizers in the macronucleus of the ciliate Tetrahymena pyriformis by staining with silver nitrate. Tsitologiia 26:849852 (in Russian with Englsh summary).

SABANEYEVA E (1997) Extrachromosomal nucleolar apparatus in the macronucleus of the ciliate Paramecium putrinum: LM, EM and Confocal Microscopy Studies. Arch Protistenkd 148: 365-373

SCHEER U, HOCK R (1999) Structure and function of the nucleolus. Curr Opin Cell Biol 11:385-390.

THIEBAUD CH (1979) Quantitative determination of amplified rDNA and its distribution during oogenesis in Xenopus laevis. Chromosoma 73:37-44.

THIRY M, LAFONTAINE DLJ (2005). Birth of a nucleolus: the evolution of nucleolar compartments. Trends Cell Biol 15:194-199.

THIRY M, LAMAYE F, LAFONTAINE DLJ (2011) The nucleolus. When two became three. Nucleus 2:289-293.

ZATSEPINA OV, HOZAK P, BABAJANYAN D, CHENTSOV Y (1988). Quantitative ultrastructural study of nucleolus-organizing regions at some stages of the cell cycle (G0-period, G2-period, mitosis). Biol Cell 62:211-218 